\title{
DOM CASMURRO: O TEXTO QUE ME ESCREVE
}

\author{
Geraldo Majela Martins* \\ Leio por instruir-me; às vezes por consolar-me. \\ Creio nos livros e adoro-os. \\ Machado de Assis \\ Entardeci possuída da infância. \\ Hilda Hilst
}

RESUMO:

0 romance Dom Casmurro é tratado a partir dos significantes: tempo, infância, amor, desejo do Outro, mulher-Capitu, lacuna, resto. Freud, Lacan e Shakespeare estão presentes como operadores de leitura.

PALAVRAS-CHAVE: Dom Casmurro, psicanálise, memória, desejo do outro, mulher.

Quero, de início, manifestar minha alegria diante do acaso. 0 auditório escolhido para a defesa pública da minha dissertação de mestrado, em Literatura Brasileira, tem o nome da professora Sônia Viegas. A professora foi, durante minha graduação em Filosofia, quem me iniciou no prazer da literatura. Por isso, dedico à sua memória este texto e desejo oferecê-10 ao homem que, além de seus oitenta anos, é o mais sábio que conheço: meu amigo, professor Martinho Trindade Monteiro.

Há quarenta anos, aproximadamente, Dom Casmurro faz parte da minha vida.

0 fio da memória alinhava o tecido esmaecido da minha infância. No ateliê da lembrança, nos suaves balanços da rede pendurada no alpendre da casa paterna, procuro a criança que fui, enovelada pelas vozes que vinham das frinchas da janela do tempo. Duas mulheres, no frio de uma manhã ensolarada de abril, enquanto preparavam seus planos de aula, discutiam e tomavam posições, ora iguais, ora diferentes, sobre uma outra mulher. 0 nome dela eu não conseguia memorizar.

| Mestre em Letras: Estudos Literários (Ârea de concentração: Literatura Brasileira), 2001. 


\section{EMTESE}

Belo Horizonte, v. 6, p. I-253, ago. 2003

Também não o reconhecia nos nomes das nossas vizinhas, nem entre os nomes das mortas que eu lia nas lápides, enquanto minha avó rezava durante nossas idas, incansáveis, ao cemitério.

Minha infância evaporava enquanto minha mãe e minha tia se entregavam aos trabalhos e aos dias da escola, além de se debruçarem sobre o destino daquela mulher. Do umbral do alpendre da casa eu ol hava para o infinito da várzea. Meus olhos escuros eram coloridos pelo verde do pasto, onde meu pai, com seus laços e cabrestos, montado no seu baio, dominava ferozes animais.

Eu queria era a vida do meu pai. No entanto, por mais que eu corresse em direção à natureza e a ele, mais forte trovejavam em mim as palavras silenciosas daquelas mulheres sobre a desconhecida, seu olhar, seu silêncio e seu enigma. Tudo isso tornou-se um relicário intocável e impronunciável dentro de mim. Na encruzilhada da minha infância, um passo de escuridão e de claridade moldava minha esfinge.

Tive medo, naquele tempo, que a mulher desconhecida viesse a estragar os dias felizes que eu sonhava para meu pai e minha mãe.

Mais tarde, já na escola, quando vi minha primeira professora, pensei que minha mãe e minha tia estivessem, talvez, se referindo e falando dela quando conversavam sobre aquela mulher cujo nome eu ainda não conseguia memorizar. Uma mistura de ternura e paixão pincelou aquele nosso encontro. Minha escola primária foi lugar de um romance, que feneceu quando minha professora partiu e voltou, muito tempo depois, com as mãos sempre atadas às de um outro homem.

Vieram os anos da escola secundária e da Universidade, longe da casa do pai. A distância da infância era tecida com a chegada da literatura e do texto da filosofia. A partir da transmissão filosófica da professora Sônia Viegas, mergulhei na literatura na busca de um sentido, naquele época, para o viver. A Filosofia me abriu dois caminhos: a psicanálise e a literatura.

A psicanálise, com o tempo, tornou-se o lugar do trabalho para viver. A literatura passou a significar a paixão para viver. Depois que deixei a casa dos meus pais, já no estrangeiro, $1 i$ e estudei somente os europeus. Exilei-me nos textos de Flaubert, Proust, Rimbaud e Gide, que me reenviaram ao escritor brasileiro Machado de Assis. A literatura brasileira era-me, até então, unheimlich. 
Em 1997, durante o colóquio Nouvelles Directions de la Recherche Proustienne, no Castelo de Cerisy-la-Salle, após as jornadas de discussões, eu voltava para meu quarto, cansado de falar e ler em francês e tomava pela primeira vez um livro, presente da professora Zélia Cerqueira, do qual eu muito já sabia. Sabia dele através de resenhas, de estudos críticos, de conferências e de aulas, mas nunca o havia 1ido. Era o livro da minha infância: Dom Casmurro. Naquele Castelo da Normandia, entre brumas e discussões proustianas, eu descobria que Dom Casmurro era uma biografia. Machado de Assis havia escrito, antes de mim e sem o saber, a minha primeira biografia.

Quando retornei a Belo Horizonte, a leitura do livro precipitou em mim um sonho sobre a minha desconhecida: Capitu. Depois de uma sessão de psicanálise, decidi que iria retornar à universidade para escrever um texto sobre Dom Casmurro. Se, como quer o poeta, sempre escrevemos para recordar a verdade, para mim, naquele momento, escrever seria uma invenção da verdade, um modo de recordá-1a mais exatamente. Meu desejo era ler Dom Casmurro a partir da história do livro na minha vida. Logo, a lembrança, o desejo e a mulher seriam os significantes que encadeariam a trama do meu texto - talhado de nódoas. Foi com temor e esforço que decidi abrir o oratório da infância, cujo curso havia sido interrompido quando a sua crisálida transbordava e derramava pelos lados da vida.

Em 1997, formulei meu desejo através de um escrito-projeto que foi aceito pela banca de seleção de mestrado e acolhido pela professora orientadora Dra. Ana Maria Clark Peres.

Lembrar, repetir e escriturar. Assim Dom Casmurro, através do trabalho da escrita - do risco -, borda com as palavras e com a tinta das lembranças uma tela. Nessa tela, os seus personagens e as suas próprias palavras são enigmas de figuras - rébus - diante dele. As palavras do narrador-autor escrevem e tentam suturar a infância perdida, o primeiro amor, a vida em breves instantes, enfim, as suas memórias e desmemórias que, entre linhas, entre palavras e entre pontos, deixam escapar o real do sexo e da morte.

No livro Dom Casmurro, memória e desmemória fiam o tecido esburacado do texto no qual se alojam o narrador e os significantes que o constituem: o tempo, a infância, o amor, o desejo do Outro, a mulher - Capitu, a lacuna e o resto dos restos. 


\section{EMTESE}

Belo Horizonte, v. 6, p. I-253, ago. 2003

Ao fazermos uma leitura-crítica, tendo em vista a idéia de Oscar Wilde de que o papel do leitor-crítico é ler e recriar, com sua própria alma, uma obra alheia, recorremos a Shakespeare, Freud e Lacan na medida em que Dom Casmurro, de maneira direta ou indireta, concorda com eles, mas também os contraria ou os ultrapassa. Não sonhamos mais com a sintese hegeliana e, sim, com a possibilidade de fazer existir um saber que seja efeito de leitura. A leitura, para nós, é consequiência da história do texto, desde sua publicação - a sua fortuna crítica -, e fundamentalmente está atrelada à história pessoal daquele que lê.

Partimos da tese de que a literatura tem o real como objeto de desejo, mesmo sabendo da impossibilidade de alcançá-10. Essa impossibilidade faz-se presente no texto de Dom Casmurro, quando o narrador tem a ilusão de, ao narrar, apreender o mistério do feminino, do desejo ou até mesmo da própria vida que se esvai durante o viver. Mesmo assim, não cede quanto ao desejo de narrar e de inscrever o que não cessa de não se escrever.

0 texto machadiano nos implicou de tal maneira, que nossa tarefa principal neste trabalho foi a de nos deixar guiar pelas entrelinhas do romance, tendo em vista os operadores de leitura: os princípios psicanalíticos.

Formulamos a afirmativa de que Dom Casmurro é um romance que faz uma borda: o nome. É uma escritura traçada por Machado de Assis, enunciada por Bentinho/ Santiago/Casmurro, agora lida por nós, acerca do desejo de Capitu. Capitu é como um rastro, pegadas, trịhas que ainda não são estradas, somente traço do um - unário. É o ausente, o não falado, a escrita, a letra, que demandam significação. Tem um estatuto de um esquecimento psíquico, ou de um esquecimento de intenção envelopando o desejo, morada do não-dito do texto, o interdito - vociferado pelo desejo do Outro.

Essa mulher sem rosto que se apresenta nas entrelinhas do texto de Machado de Assis funciona como um enigma de figuras (ein Bilderrätsel) oníricas, ou rébus, convocadores de significâncias. Seu nome, Capitolina, Capitu, diz pouco o que ela é. Se buscarmos as metáforas do seu ser, descobrimos seu olhar de cigana obliqua e dissimulada, seus olhos de ressaca, seu primeiro beijo testemunhado pela mãe, ou sua lágrima na cena do enterro de Escobar. Tudo isso é de uma inconsistência tal de significados, que só nos resta fazer margem, borda, bascular o que é impossivel de dizer: Capitu. 
Capitu captura os homens e os críticos e os transforma em caça para os seus cães. É outro nome de Diana. É uma mulher como sintoma dos homens. É êxtase estético do autor. As lembranças narradas sobre ela, sobre seu romance com Bentinho ou com Bento Santiago e, quem sabe lá, com outro homem, têm uma falta de realidade tal que nada mais são do que substituição de outra coisa. A tessitura das palavras, em feixes de lembranças, na obra machadiana marca a verdade não-toda. Capitu deixa os homens, como Santiago, aturdidos com a dúvida e deixa as mulheres a interrogarem: o que ela quer? Logo, o estilo não é mais o homem mas, sim, o objeto-quase causa de desejo: Capitu.

É por esse viés que nos aproximamos do texto de Dom Casmurro, não para compreendê-10 bem, inteiramente, nem para 1ê-10 direito, nem para bem sabê-10, já que tudo isso para nós é da ordem do impossível.

Apesar das semelhanças entre a construção analítica e a construção literária, é preciso assinalar que Dom Casmurro não é um sujeito falante, aquele da associação livre, ele é uma personagem e, como tal, não é real. Logo, ele não é um sujeito passível de uma psicanálise.

Durante muito tempo a crítica literária comparou esse romance de Machado com o Otelo de Shakespeare, tendo em vista o ciúme dos dois personagens. Neste nosso trabalho convocamos outro texto de Shakesperare, o Hamlet, para lermos o texto machadiano. Delimitamos semelhanças e diferenças entre Casmurro e Hamlet, na medida em que os dois, com sua retórica, encobrem sua desrazão. Tanto Hamlet se faz passar por louco, para atingir seus fins, como Casmurro passa-se por lúcido, para atingir seu fim específico de nos convencer de um adultério.

Pode-se, assim, ensaiar, repetir e insistir, junto com Dom Casmurro, que 0 texto escreve aquilo que não pode ser dito. 0 que ele diz sem saber que o diz é que a verdade é não-toda e ele só pode semidizê-la. Se Freud indicou que é preciso tomar o desejo (Wunsch) ao pé da letra, o que Dom Casmurro nos permite é trilhá-10 como uma voluta que, através das letras, fonemas, orações, construções textuais, enfim, livro, registra aquilo que é impossível de capturar: o eu.

Dom Casmurro sabe, desde o início, sem o saber, que sua narrativa é lacunar e que ela só o leva à "ilusão" das inquietas sombras. Mesmo assim quando 


\section{EMTESE}

Belo Horizonte, v. 6, p. I-253, ago. 2003

narra o faz como quem "horta", "jardina", lê e vive. Na abertura do livro adianta para seu leitor que o seu objetivo de atar as duas pontas da vida fracassara. Ele avisa: "não consegui recompor o que foi nem o que fui".

0 texto de Dom Casmurro é invenção no campo do significante, a partir de uma língua perdida, aquela que se foi, que se evaporou no instante em que a vida era vivida. Se, a princípio, Dom Casmurro deseja atar as duas pontas da vida, ele anuncia o desejo, não para objetivá-10 mas, simplesmente, para mantê-10: temos assim uma realização de desejo e não sua satisfação.

$\mathrm{Se}$, no texto de Hamlet, o personagem transita entre dois mundos - 0 dos vivos e o dos mortos -, chegando a sua dúvida cruel entre "ser ou não ser", Dom Casmurro, em sua suposta identificação com o Hamlet, desvia-se de Hamlet para instaurar não o ser ou o não ser, mas o falto eu mesmo. Assim nasce a narrativa, costurada pelas lembranças da infância, morada do romance familiar.

Se Dom Casmurro se lembra da sua infância e do seu primeiro amor é para instaurá-los como perda e não para restaurá-los - esta é a escritura casmurriana. Desta maneira, só podemos tocar no eu que falta através da fruição dos lábios que narram. Ele, o eu, é narrado mas não fala, não pode ser dito e, no entanto, é falado.

A psicanálise, a partir das suas construções, nos revela o sujeito falante e falado que tem seu inconsciente estruturado pela linguagem. A tragédia do Hamlet, no seu descrédito com as palavras, nos leva ao silêncio dos restos. 0 texto machadiano, diferentemente, nos conduz não para o silêncio sepulcral, mas para 0 resto dos restos. 0 resto não fecha o livro, mas causa o devir de outras leituras para as quais o narrador nos convoca.

0 encontro que estabelecemos entre os textos da psicanálise e os textos de Shakespeare e Machado, não teve como pressuposto reduzir esses últimos aos primeiros. 0 que ensaiamos o tempo todo foi a intertextualidade, quer dizer, a produção de uma leitura a partir desse encontro. Mesmo quando Dom Casmurro e a teoria psicanalítica se debruçam sobre as lembranças, as memórias e as desmemórias, eles o fazem com objetivos diferentes, alcançando cada um sua saída.

0 mesmo se dá entre Hamlet e Dom Casmurro. São textos que evidenciam a dúvida dos personagens, o medo da morte, o enigma do feminino e o desejo; no 
entanto, eles constroem estes temas e os evidenciam de maneira muito particular. Dom Casmurro, para nós, marca sua singularidade na construção acerca do eu, que não tem a marca do cartesianismo, nem o desejo do absoluto hegeliano. Sua marca, singular, está no enunciado: "falto eu mesmo, e esta lacuna é tudo". Dom Casmurro é uma escritura do não-saber, cujo efeito é a lacuna.

Dom Casmurro não é um livro sobre a morte, nem tampouco sobre a vida, mas relativo à vida. É um livro sobre o que deseja uma mulher, já que esta carrega, desde o início, a vida e a morte. Capitu-menina-A Mulher passa, assim, a ser causa de toda a trama do livro, como também mulher-causa da existência da pergunta que mantém o narrador e o leitor vivos. Se a imagem de Capitu persegue o narrador nas suas fantasias e no seu pensamento, e durante toda a sua vida, como ele, somos capturados pelo enigma daquela que se desloca no discurso dos capítulos e se instaura definitivo no suposto fim: e bem, e o resto?

Capitu e os capítulos deixam o texto esburacado, sem término. 0 narradorautor maneja a construção do texto literário tentando apreender aquilo que nos escapa e sobra: Capitu e os capítulos. Capitu(rá-)los, já que sempre escapam à significação, é o que repetimos.

Os capítulos brevíssimos compõem um só verso, rasurando e ferindo o real da mulher e da morte. A forma do texto se constrói com base em ladrilhos, de modo que esses longos e curtos capítulos são edifícios, compostos por numerosos significantes-ladrilhos, melhor ou pior cimentados. 0 que fia a palavra no texto é a lacuna do falto eu mesmo. A ferida que tudo isso causa é suturada pelas orações intermináveis e pelas reticências que tentam estancar o real que atravessa 0 texto nas suas entrelinhas. Dessa maneira, o livro e os capítulos só têm aparência de breves, já que neles inscreve-se o desejo, que dura a eternidade do instante.

Sempre desconfiamos que a referência constante e a importância que 0 livro Dom Casmurro teve e continua tendo, para a crítica e para o leitor, são porque nele habita uma das questões fundamentais dos homens e das mulheres: o que quer uma mulher? Essa questão se desdobra em outra: o que quer a vida?

Finalmente, concluímos retomando a tese de que o texto de Machado de Assis, as lembranças de Casmurro e nosso trabalho nada mais são do que uma tela 


\section{EMTESE}

Belo Horizonte, v. 6, p. I-253, ago. 2003

escrita, onde as imagens são produzidas pelo discurso, forma que Machado de Assis, Casmurro e nós encontramos para margear o impossível de dizer: o real.

E bem. E o resto?

Podemos dizer, ainda, neste fim-abertura de um outro texto que começa a balbuciar, que o sujeito que narra não é o sujeito narrado. Ele narra não o sujeito do vivido - o sujeito factual - mas sim aquele que surge nas entrelinhas do texto e sua dimensão é a ficção. Aquele que viveu desapareceu no vivido. Já o narrado emerge das lembranças e das narrativas, por isso tem o valor da lembrança. Dom Casmurro não faz síntese, nem conciliação entre a vida e a narrativa. Uma visita a outra, mas uma não é a outra. Uma diz da outra nos traços que repetem do real. Já que o que falta é eu mesmo, o que nos resta, através do trabalho, é inventar a significância da vida. Se existe a significância do sonho para Freud, podemos pensar que Dom Casmurro descobriu a significância do falto eu mesmo. Deixemos, mais uma vez, as palavras com o narrador-autor: "Tudo é dar-lhe uma idéia e encher o centro que falta".

0 eu unificador das experiências e conciliador das sinteses é o grande ausente. 0 narrador chega a nos dizer que "palavra puxa palavra". Logo, a palavra que puxa a palavra é sua invenção, sua ficção literária, que dá consistência àquilo que falta, o eu mesmo. Essa lacuna é o seu debuxo primitivo que o faz escrever na trama do desejo: tela da lembrança.

0 que quisemos, neste nosso percurso, foi não tomar Dom Casmurro como pretexto para confirmar alguns pontos da constituição subjetiva. Assim, ele passa à função de causa da produção introduzindo o leitor. Esse leitor torna-se o sujeito que se divide diante do texto e é convidado a pôr algo de si numa dimensão que compromete seu desejo. A lacuna instaurada pelo "falto eu mesmo" não pode ser tamponada pelas lembranças, nem quando escritas. As lembranças somente podem anunciá-la.

Com a psicanálise, ou até mesmo sem ela, todos acabam sempre se tornando um personagem do romance que é a sua própria vida.

Ao terminar a escritura do texto, tive um sonho! Não me restou quase qualquer lembrança dele. Durante as associações que formulei sobre esse sonho, um enunciado em ruínas vociferou: "Este texto que eu acabei de escrever...". Antes que 
eu completasse a frase fui interrompido por uma outra voz: "Não foi você quem o escreveu, foi ele quem te escreveu".

0 texto me escreveu: travessia de um palude. Será que é por isso que tenho perdido o desejo de recordar? E o pó do esquecimento deu lugar ao luto? Minha casmurrice, deixei-a no branco das folhas e agora falta "eu mesmo" e esta lacuna será tudo. Deste processo, herdei algo que não recebi de ninguém: o desejo de viver.

ABSTRACT:

This essay discusses the novel Dom Casmurro, focusing on the following terms: time, childhood, love, the desire of the other, Capitu, gap, remains. This reading is informed by Freud, Lacan and Shakespeare.

KEY WORDS: Dom Casmurro, psychoanalysis, memory, desire of the other, woman.

REFERÊNCIAS BIBLIOGRÁFICAS

MACHADO DE ASSIS. Dom Casmurro. Org. Afrânio Coutinho. Rio de Janeiro: Nova Aguilar, 1997. p. 807-944. (Obra Completa, v.1).

MARTINS, Geraldo Majela. Dom Casmurro - tela escrita da lembrança: a trama do desejo. Belo Horizonte: Faculdade de Letras da Universidade Federal de Minas Gerais - UFMG, 2001. 144p. (Dissertação, Mestrado em Literatura Brasileira). 